\title{
Simulation of nutrient uptake by a growing root system considering increasing root density and inter-root competition
}

\author{
E. HOFFLAND ${ }^{1}$, H.S. BLOEMHOF ${ }^{1}$, P.A. LEFFELAAR ${ }^{2}$, G.R. FINDENEGG ${ }^{1}$ and J.A. \\ NELEMANS ${ }^{1}$ \\ ${ }^{1}$ Department of Soil Science and Plant Nutrition, Wageningen Agricultural University, P.O. Box 8005, \\ 6700 EC Wageningen, The Netherlands, and ${ }^{2}$ Department of Theoretical Production Ecology, Wageningen \\ Agricultural University, Bornsesteeg 65, 6708 PD Wageningen, The Netherlands
}

Key words: Brassica napus L., CSMP, diffusion, inter-root competition, nitrate, mass flow, nutrient uptake, quartz sand, simulation model, zero-sink

\begin{abstract}
A simulation model is presented which describes uptake of a growth limiting nutrient from soil by a growing root system. The root surface is supposed to behave like a zero-sink. Uptake of the nutrient is therefore determined by the rate of nutrient supply to the root surface by mass flow and diffusion. Inter-root competition and time dependent root density are accounted for by assigning to each root a finite cylindrical soil volume that delivers nutrients. The radius of these cylinders declines with increasing root density. Experiments with rape plants grown on quartz sand were used to evaluate the model. Simulated nitrogen uptake agreed well with observed uptake under nitrogen limiting conditions. In case no nitrogen limitation occurred nitrogen uptake was overestimated by the model, probably because the roots did not behave like a zero-sink any more.
\end{abstract}

\section{Introduction}

Simulation models for nutrient uptake have frequently been used in the evaluation of the effect of soil and root characteristics on nutrient uptake. Uptake models allowing for growing roots were developed by Nye et al. (1975), Claassen and Barber (1976) and Cushman (1979). No effects of time dependent root density on interroot competition are included in these models. This hampers their use in the simulation of experiments with rapidly increasing root densities, as usually found in pot experiments.

Claassen and Barber did not include inter-root competition because they assumed that roots exploit a cylindrical soil volume with a constant solute concentration at the outer boundary. Their model overestimates nutrient uptake if nutrients are mobile (Silberbush and Barber, 1983). In Cushman's model the cylinder wall is impermeable to nutrients and the nutrient concentration at the cylinder wall declines in consequence of uptake. Though root growth is considered in this model, root density is kept constant in time i.e. the soil volume available per unit root length does not change with increasing root length. Therefore, in a situation with high root growth rates, this model also overestimates nutrient uptake (Silberbush and Barber, 1983). Baldwin et al. (1973) proposed an equation to extend Nye's model in which the effect of increasing root density on inter-root competition is described: the radius of each finite soil volume surrounding a root is a function of root density, assuming that each newly formed root samples the mean nutrient concentration. The validity of this assumption is questionable, because it is well established that roots branch mostly in zones of highest nutrient concentration (Russell, 1977). Yet, Nye's model was only tested under condi- 
tions where inter-root competition was not expected so that the equation of Baldwin et al. was not included in the model. Overestimation of nutrient uptake by Nye's model was again attributed to inter-root competition (Brewster et al., 1975).

The objective of this paper is to present a new simulation methodology that considers inter-root competition in a soil with increasing root density. Simulation results and experimental data will be compared.

\section{Methods}

\section{Theoretical}

The simulation model developed describes nutrient uptake by a root system that grows in a restricted soil volume. Each root is assigned a finite cylindrical soil volume delivering nutrients, and the soil volume per unit root length declines with increasing root density. Uptake of nutrients by the root, transport of nutrients to the root surface and the effect of increasing root density are considered as the three main components of this model and will be described subsequently.
Each timestep, the equation of continuity for cylindrical co-ordinates is solved:

$$
\begin{aligned}
\frac{\delta \mathrm{C}}{\delta \mathrm{t}}= & -\frac{1}{\mathrm{r}} \times \frac{\delta}{\delta \mathrm{r}}(\mathrm{r} \times \mathrm{F})+\mathrm{S} \quad \text { (Eq. } 1.9 \text { in Nye } \\
& \text { and Tinker, 1977) }
\end{aligned}
$$

The initial boundary condition is described by:

$$
\mathrm{t}=0 \quad \mathrm{r}>\mathrm{r}_{0} \quad \mathrm{C}=\mathrm{C}_{\mathrm{i}}
$$

The sink term $S$ represents nutrient uptake by the root that is situated in the centre of a soil cylinder. All nutrients arriving at the root surface are supposed to be absorbed, i.e. the root surface is supposed to behave like a zero-sink. Root hairs are assumed to be so abundantly present that they are regarded to enlarge the root surfacial area to one located near their tips (Nye, 1966). The boundary condition at the tips of the root hairs is therefore:

$$
\mathrm{t}>0 \quad \mathrm{r}=\mathrm{r}_{0} \quad \mathrm{C}_{0}=0
$$

\begin{tabular}{|c|c|c|}
\hline \multicolumn{3}{|c|}{ List of symbols } \\
\hline symbol & definition & units \\
\hline A & total surface area of the pot & $\mathrm{cm}^{2}$ \\
\hline $\mathrm{C}$ & ion concentration in soil solution & $\mu \mathrm{mol} \times \mathrm{cm}^{-3}$ \\
\hline $\mathrm{C}_{0}$ & ion concentration in the soil solution at the root surface & $\mu \mathrm{mol} \times \mathrm{cm}^{-3}$ \\
\hline $\mathrm{C}_{\mathrm{i}}$ & initial ion concentration in the soil solution & $\mu \mathrm{mol} \times \mathrm{cm}^{-3}$ \\
\hline $\mathrm{D}_{0}$ & diffusion coefficient of ion in free solution & $\mathrm{cm}^{2} \times$ day $^{-1}$ \\
\hline $\mathrm{D}_{\mathrm{e}}$ & effective diffusion coefficient & $\mathrm{cm}^{2} \times$ day $^{-1}$ \\
\hline $\mathrm{F}$ & flux of nutrients to root surface & $\mu \mathrm{mol} \times \mathrm{cm}^{-2} \times \mathrm{day}^{-1}$ \\
\hline $\mathrm{F}_{1}$ & total flux of the nutrient across the outer boundary of the soil cylinder & $\mu \mathrm{mol} \times \mathrm{cm}^{-2} \times$ day $^{-1}$ \\
\hline f & tortuosity factor & - \\
\hline $\mathrm{L}_{c}$ & critical root length & $\mathrm{cm}$ \\
\hline $\mathrm{M}_{\mathrm{t}}$ & amount of $\mathrm{P}$ on infinite sink & $\mu \mathrm{mol} \times \mathrm{cm}^{-2}$ \\
\hline $\mathrm{n}$ & number of plants per pot & - \\
\hline $\mathrm{r}$ & radial distance from root axis & $\mathrm{cm}$ \\
\hline$r_{0}$ & root radius + root hair length & $\mathrm{cm}$ \\
\hline$r_{1}$ & radius of the soil cylinder surrounding each root & $\mathrm{cm}$ \\
\hline $\mathrm{S}$ & sink term & $\mu \mathrm{mol} \times \mathrm{cm}^{-3} \times$ day $^{-1}$ \\
\hline $\mathrm{t}$ & time & day \\
\hline $\mathrm{V}_{1}$ & total volume of the pot or soil layer considered & $\mathrm{cm}^{3}$ \\
\hline $\mathrm{v}$ & inward water flux & $\mathrm{cm}^{3} \times \mathrm{cm}^{-2} \times \mathrm{day}^{-1}$ \\
\hline$v_{0}$ & water flux across the root surface & $\mathrm{cm}^{3} \times \mathrm{cm}^{-2} \times$ day $^{-1}$ \\
\hline$v_{1}$ & water flux across the outer boundary of the soil cylinder & $\mathrm{cm}^{3} \times \mathrm{cm}^{-2} \times$ day $^{-1}$ \\
\hline$\theta$ & volumetric moisture content & $\mathrm{cm}^{3} \times \mathrm{cm}^{-3}$ \\
\hline
\end{tabular}

The rate of nutrient supply to the root surface by mass flow and diffusion is described according 
to

$$
\mathrm{F}=-\mathrm{D}_{\mathrm{e}} \times \frac{\mathrm{dC}}{\mathrm{dr}}+\mathrm{v} \times \mathrm{C} \quad \text { (Eq. } 1.5 \text { in Nye and }
$$$$
\text { Tinker, 1977) }
$$

with

$$
\mathrm{D}_{\mathrm{e}}=\theta \times \mathrm{f} \times \mathrm{D}_{0} \quad(\text { Nye, 1968) }
$$

Buffering of the solute by the soil is not included.

Inter-root competition for nutrients is accounted for by assigning finite cylindrical volumes with radius $r_{1}$ to each root. Water but no nutrients can pass the cylinder wall, similarly to Cushman's model. The boundary condition at $r_{1}$ is therefore:

$$
\mathrm{t}>0 \quad \mathrm{r}=\mathrm{r}_{1} \quad \mathrm{~F}_{1}=0 \quad \mathrm{v}_{1}=\mathrm{r}_{0} \times \mathrm{v}_{0} / \mathrm{r}_{1}
$$

The initial radius of each soil cylinder is calculated by

$$
\mathrm{t}=0 \quad \mathrm{r}_{1}=\sqrt{ }(\mathrm{A} /(\pi \times \mathrm{n}))
$$

assuming that each plant starts with one root growing in vertical direction. Each of these parallel soil cylinders is divided into a number of concentric compartments (shells). The time course of the concentration of nutrients in the soil solution in each of these shells is described according to the above mentioned equations.

Each time the actual root length exceeds a certain critical root length $L_{c}$, the outer shell of each soil cylinder is stripped off and their material is used to form new soil cylinders that are assigned to the newly developing roots. These new cylinders have the same radius as the older ones after stripping and they are divided into the same number of shells as left over in the stripped cylinders.

The solute concentration in the newly formed soil cylinders is initially the same as that in the outer stripped shells, where the nutrient concentrations are highest. This can be interpreted as new roots penetrating between older ones, in zones of highest nutrient concentration. After formation, a new time dependent nutrient concentration gradient is calculated in each soil cylinder.
The critical root length $\mathrm{L}_{\mathrm{c}}$ is a function of the current radius of the soil cylinder surrounding each root, according to the following equation:

$$
\mathrm{L}_{\mathrm{c}}=\mathrm{V}_{1} /\left(\pi \times \mathrm{r}_{1}^{2}\right)
$$

Up to the first moment that a critical root length is reached and the stripping procedure is executed, the uptake calculation takes place with a root length that is half of the first critical root length. After reaching the first critical root length, the calculations are performed with the arithmetic average of the previous and newly calculated critical root length. Therefore, during the first half of each period nutrient uptake is overestimated, whereas during the last one it is underestimated. On the average this should yield reasonable results. This method spares CPUtime in comparison with a method by which uptake is calculated with the actual root length.

Additional conditions for which the model was developed are: neither temporal nor spatial gradients in volumetric moisture content occur, there is no nutrient production, no spatial gradient in root density and nutrient uptake is homogeneous along the root.

Plant parameters needed to run the model are: root length as a function of time, radius of the root, root hair length and the water uptake per unit root length as a function of time. Soil parameters needed are: the volumetric water content $\theta$, the tortuosity factor $\mathrm{f}, \mathrm{D}_{0}$ and the initial concentration $\mathrm{C}_{\mathrm{i}}$ of the nutrient.

The CSMP-III simulation model was executed on a VAX computer using the variable time step integration method of Runge-Kutta Simpson. A copy of the model is available at request from the first authoress (E.H.).

\section{Experimental}

Experiments were done to provide the above mentioned soil and plant parameters for the model and to evaluate the model by comparing predicted nitrate uptake with observed nitrate uptake by rape plants growing in cylindrical pots on quartz sand.

Measurement of $f$ as function of $\theta$ The relation between the tortuosity factor $\mathrm{f}$ and $\theta$ was de- 
termined by a method similar to that described by Vaidyanathan and Nye (1966). Iron oxide paper $(2 \times 4 \mathrm{~cm}$; see Van der Zee et al., 1987) was used as an "infinite sink" for phosphate ions. Quartz sand was washed with $1.5 \mathrm{M} \mathrm{HCl}$ and demineralized water respectively and subsequently heated at $900^{\circ} \mathrm{C}$ to make it inert with respect to phosphate so that the behaviour of phosphate did not differ essentially from that of nitrate. The pretreated sand was mixed with a nutrient solution containing $5.0 \mathrm{~m} M \quad \mathrm{KH}_{2} \mathrm{PO}_{4}$ and packed into Petri dishes (dry bulk density $1.28 \mathrm{~g} \times \mathrm{cm}^{-3}$ ) with a piece of iron oxide paper on the bottom. The moisture content of the iron oxide paper had previously been equilibrated with quartz sand that was moistened with demineralized water up to the desired $\theta$. To prevent sagging of the nutrient solution, the dishes were placed in an end-over-end shaker. After about 3 hours contact time the iron oxide paper was removed, washed in demineralized water, air dried, and extracted in $5 \mathrm{ml} 0.2 \mathrm{M} \mathrm{H}_{2} \mathrm{SO}_{4}$. The extract was analyzed for phosphate by the molybdenum-blue method. $\mathrm{D}_{\mathrm{e}}$ was then calculated from the amount of phosphate on the paper by

$$
\begin{aligned}
D_{e}= & \frac{\pi \times M_{t}^{2}}{4 \times C^{2} \times t} \quad \text { (derived from Eq. } 3.15 \text { in } \\
& \text { Crank, 1975) }
\end{aligned}
$$

and $\mathrm{f}$ by

$$
\mathrm{f}=\frac{\mathrm{D}_{\mathrm{e}}}{\theta \times \mathrm{D}_{0}} \quad \text { (derived from Nye, 1968). }
$$

Plant growth Rape plants (Brassica napus L. $\mathrm{cv}$. Jetneuf) were grown for 16 days on quartz sand in cylindrical pots at two nitrate levels. Ten plants of rape were grown in 3-1 pots $(\phi 12 \mathrm{~cm}$, height $27 \mathrm{~cm}$ ). Each pot contained a mixture of $3.2 \mathrm{~kg}$ quartz sand (dry bulk density $1.28 \mathrm{~g} \times$ $\mathrm{cm}^{-3}$ ) and $575 \mathrm{ml}$ (high moisture level) or $385 \mathrm{ml}$ (low moisture level) nutrient solution. In the $1.5 \mathrm{~m} M$-treatment $1.5 \mathrm{~m} M \mathrm{KNO}_{3}$ and $3.5 \mathrm{~m} M$ $\mathrm{KCl}$ were added to the nutrient solution which consisted of $5.0 \mathrm{mM} \mathrm{CaCl}, 2.0 \mathrm{mM} \mathrm{MgSO}$, $2.0 \mathrm{mM} \mathrm{KH} \mathrm{KH}_{2} \mathrm{PO}_{4}$ and trace elements (in $\mathrm{mg}$ $\mathrm{L}^{-1}$ ): $\mathrm{Fe}$ (as FeEDTA) 4.6; B 0.5; Mn 0.5; Zn 0.05; $\mathrm{Cu} 0.02$; Mo 0.01. In the $5.0 \mathrm{~m} M$-treatment
$5.0 \mathrm{~m} M \mathrm{KNO}_{3}$ was added. The plants were grown in a growth chamber at $20^{\circ} \mathrm{C}$, a $16 \mathrm{~h}$ light $\left(70 \mathrm{~W} \times \mathrm{m}^{-2}\right)-8 \mathrm{~h}$ dark cycle and a relative humidity of about $80 \%$. Evaporation (from blanc pots) and evapotranspiration were measured daily and the moisture level was readjusted daily. The beginning of the experiment, $t=0$ was defined as the moment at which half of the plants was germinated. At each harvest, a number of pots was deep frozen and divided into five layers of $4.5 \mathrm{~cm}$ height by sawing. The layers are referred to as layer I through V, from top to bottom. Root length, $\theta$ and nitrate concentration in the soil solution were measured in each layer. Nitrate was measured after extraction of dried sand by automatic spectrophotometry after reduction to nitrite. From other pots, plant material was dried and analyzed for $\mathrm{N}$ after wet digestion in a $\mathrm{H}_{2} \mathrm{SO}_{4}$-Se-salicylic acid mixture with addition of $\mathrm{H}_{2} \mathrm{O}_{2}$. Total $\mathrm{N}$ was determined by the indophenol blue method.

\section{Results}

\section{Experimental}

Measurement of $f$ as function of $\theta$ The value of $\mathrm{f}$ for different volumetric moisture contents is shown in Figure 1.

Plant growth Substantial differences in volumetric moisture content $\theta$ (Table 1) and in the nitrate concentration in the soil solution (Table 2) were found among the five layers of one pot. In pots without plants neither of these two gradients changed significantly during the experiment. Differences of $\theta$ with depth resulted from the poor water holding capacity of the quartz sand used. The difference in $\mathrm{N}$ concentration among layers is probably caused by the fact that evaporation from layer I was compensated by supplying demineralized water via a tube positioned with its bottom in layer II.

Also considerable difference in root length among the layers (Table 3 ) was found within one treatment. There was no difference among the five layers with respect to root radius $(0.02 \mathrm{~cm})$ and root hair length $( \pm 0.05 \mathrm{~cm})$.

Water uptake per $\mathrm{cm}$ root declined from 


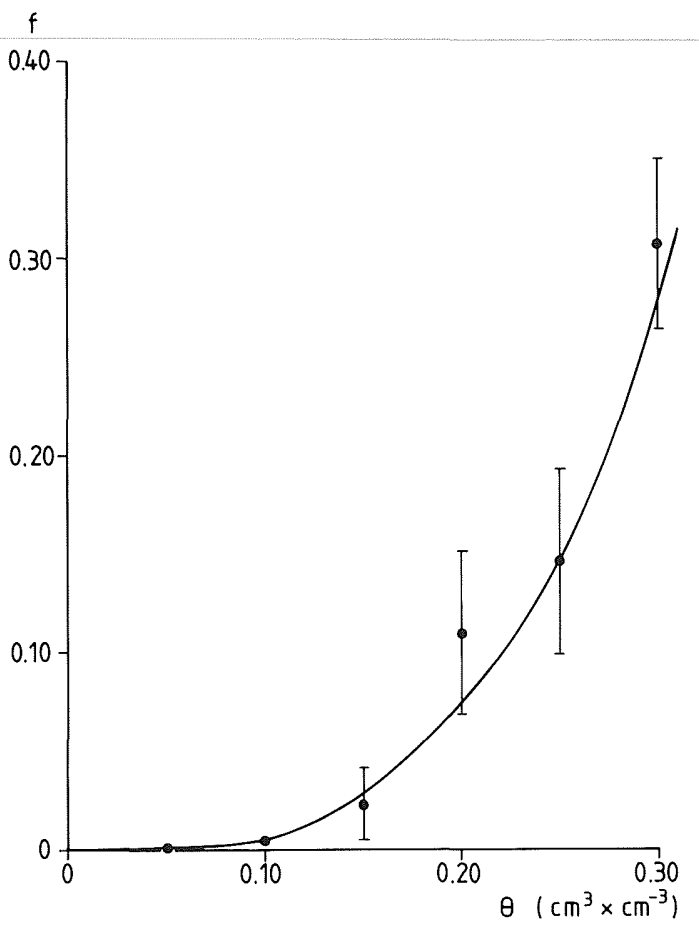

Fig. 1. Experimentally determined relation between $\mathrm{f}$ and $\theta$ (means \pm s.d., $n=5$ ) and relation used in the simulation model (-).

$0.028 \mathrm{~cm}^{3} \times \mathrm{day}^{-1}$ at the beginning of the experiment to $0.002 \mathrm{~cm}^{3} \times$ day $^{-1}$ at the end. No significant differences were found among the three treatments.

Total $\mathrm{N}$ uptake per pot and tissue $\mathrm{N}$ concentration as a function of time for each treatment are depicted in Figures 2 and 3, respectively. In the high moisture level treatments no nitrate was left in the soil solution at the end of the experiment, while in the low moisture level treatment about $30 \%$ of the added nitrogen was left in the nutrient solution (mainly in layers IV and V).
Table-1. Volumetric water content per layer for each treatment. Values are means of two replicates

\begin{tabular}{llll}
\hline $\begin{array}{l}\text { N level }(\mathrm{m} M): \\
\text { Moisture level: }\end{array}$ & $\begin{array}{l}1.5 \\
\text { high }\end{array}$ & $\begin{array}{l}5.0 \\
\text { high }\end{array}$ & $\begin{array}{l}5.0 \\
\text { low }\end{array}$ \\
\hline Layer & $\begin{array}{l}\text { Volumetric water } \\
\text { content }\left(\mathrm{cm}^{3} \times \mathrm{cm}^{-3}\right)\end{array}$ \\
\hline I & 0.13 & 0.13 & 0.10 \\
II & 0.19 & 0.19 & 0.08 \\
III & 0.23 & 0.23 & 0.15 \\
IV & 0.28 & 0.28 & 0.17 \\
V & 0.30 & 0.30 & 0.21 \\
\hline
\end{tabular}

Table 2. Concentration $\mathrm{N}$ in the soil solution per layer at $t=0$ for each treatment. Values are means of two replicates

\begin{tabular}{llll}
\hline $\begin{array}{l}\text { N level }(\mathrm{m} M): \\
\text { Moisture level: }\end{array}$ & $\begin{array}{l}1.5 \\
\text { high }\end{array}$ & $\begin{array}{l}5.0 \\
\text { high }\end{array}$ & $\begin{array}{l}5.0 \\
\text { low }\end{array}$ \\
\hline Layer & \multicolumn{2}{l}{$\begin{array}{l}\text { N concentration in } \\
\text { soil solution }(\mathrm{m} M)\end{array}$} \\
& 2.6 & 9.6 & 7.7 \\
I & 0.5 & 2.7 & 1.9 \\
II & 1.2 & 3.9 & 4.9 \\
III & 1.3 & 5.6 & 6.4 \\
IV & 1.6 & 5.1 & 4.8 \\
V & & &
\end{tabular}

\section{Simulation}

To approximate the model conditions of absence of spatial gradients in moisture level and root density, the simulation model was run for each of the five soil layers considered in the experiment. Total $\mathrm{N}$ uptake per pot was calculated by summation.

Soil parameters presented in Table 1 and Figure 1 were used to run the model. The simulation was initialized with respect to the $\mathrm{N}$ concentration in the soil solution with data given in

Table 3. Root length per layer as a function of time for each treatment. Values are means of two replicates.

\begin{tabular}{|c|c|c|c|c|c|c|c|c|c|c|c|c|c|c|c|}
\hline \multirow[t]{3}{*}{ Layer } & \multicolumn{5}{|c|}{$1.5 \mathrm{~m} M \mathrm{~N}$ high moisture level } & \multicolumn{5}{|c|}{$5.0 \mathrm{~m} M \mathrm{~N}$ high moisture level } & \multicolumn{5}{|c|}{$5.0 \mathrm{~m} M \mathrm{~N}$ low moisture level } \\
\hline & \multicolumn{15}{|c|}{ Root length $(\mathrm{m})$ after $0,3,7,10$ or 16 days } \\
\hline & 0 & 3 & 7 & 10 & 16 & 0 & 3 & 7 & 10 & 16 & 0 & 3 & 7 & 10 & 16 \\
\hline I & 0.3 & 1.6 & 5.0 & 6.4 & 12.5 & 0.3 & 1.2 & 6.4 & 8.4 & 24.8 & 0.3 & 0.3 & 4.3 & 7.2 & 10.0 \\
\hline II & 0.1 & 0.5 & 3.7 & 4.1 & 6.6 & 0.1 & 0.3 & 3.5 & 7.2 & 10.9 & 0.1 & 0.1 & 2.5 & 7.1 & 5.5 \\
\hline III & 0.0 & 0.2 & 2.8 & 4.5 & 8.3 & 0.0 & 0.2 & 3.3 & 7.2 & 17.0 & 0.0 & 0.0 & 1.9 & 9.3 & 11.8 \\
\hline IV & 0.0 & 0.1 & 1.4 & 4.2 & 11.7 & 0.0 & 0.1 & 2.3 & 5.7 & 19.1 & 0.0 & 0.0 & 1.4 & 8.0 & 17.7 \\
\hline V & 0.0 & 0.0 & 0.8 & 2.0 & 19.7 & 0.0 & 0.1 & 0.8 & 4.0 & 41.7 & 0.0 & 0.0 & 0.6 & 3.9 & 25.1 \\
\hline
\end{tabular}




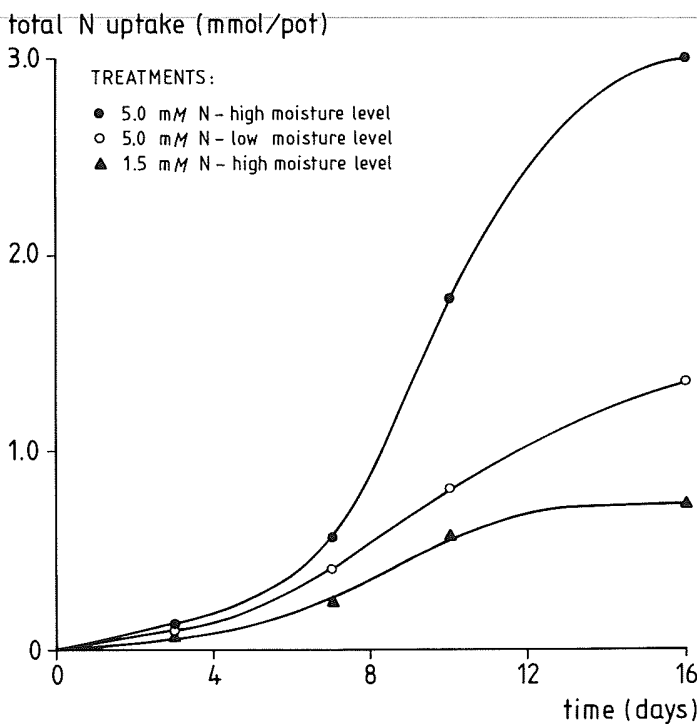

Fig. 2. N uptake by rape plants grown on quartz sand as a function of time. Values are means of three replicates.

Table 2. Root length (Table 3) and water uptake per $\mathrm{cm}$ root as a function of time were used as forcing functions. The initial number of shells surrounding a root was set to 27. During the simulation period this number declined to 1 at $\mathrm{t}=16$ days in consequence of root growth.

Predicted and observed $\mathrm{N}$ uptake are shown in Figure 4.

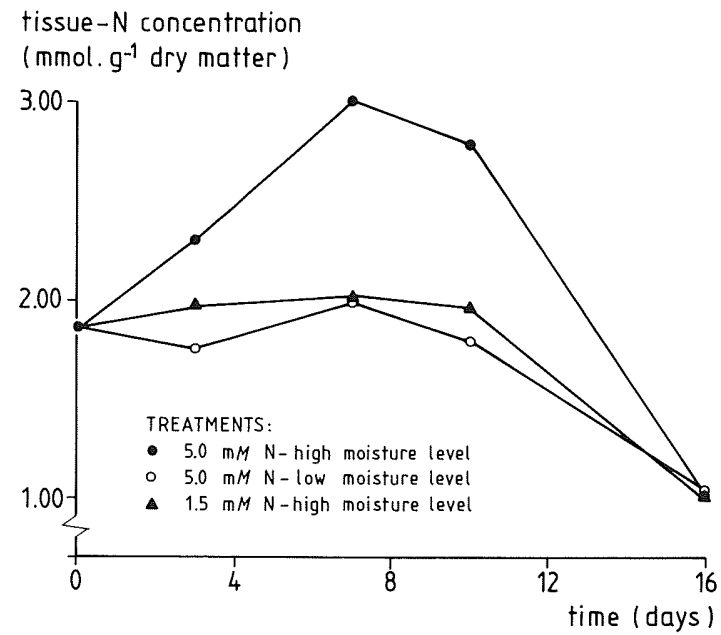

Fig. 3. N concentration in dry matter of rape plants grown on quartz sand as a function of time. Values are means of three replicates.

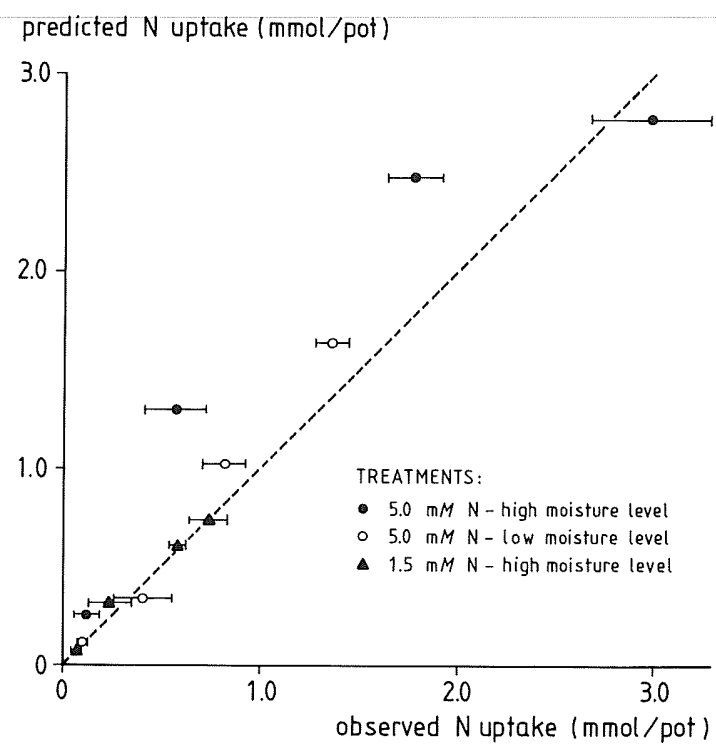

Fig. 4. Comparison of observed $\mathrm{N}$ uptake (means \pm s.d., $n=3$ ) by rape with predicted $\mathrm{N}$ uptake for three treatments. The dashed line is where predicted uptake equals observed uptake.

\section{Discussion}

Comparison of predicted $\mathrm{N}$ uptake with observed uptake (Fig. 4) shows good agreement for the $1.5 \mathrm{~m} M$-high moisture level and $5.0 \mathrm{~m} M$-low moisture level treatment. When predicted and observed $\mathrm{N}$ uptake are compared per layer (data not shown) for the $1.5 \mathrm{~m} M$-high moisture level treatment, there is a close agreement in each layer. This means that both nutrient transport to the root surface and the effect of increasing root density on nutrient uptake are simulated well. In the $5.0 \mathrm{~m} M$-low moisture level treatment a slight overestimation of $\mathrm{N}$ uptake occurs after 10 days of growth. This overestimation originates from layer IV and $\mathrm{V}$, with relatively high amounts of $\mathrm{N}$ available in the soil solution.

The model overestimates $\mathrm{N}$ uptake for the $5.0 \mathrm{~m} M$-high moisture level treatment (Fig. 4). Figure 3 shows that tissue $\mathrm{N}$ concentration in this treatment at $\mathrm{t}=7$ and $\mathrm{t}=10$ days is about $3 \mathrm{mmol} \times \mathrm{g}^{-1}$ dry matter, which is the concentration of $\mathrm{N}$ sufficient rape plants (Hoffland $e t$ al., 1989). Nitrate was apparently not growth limiting and therefore, it is very likely that the model assumption that roots act like a zero-sink is not met under these conditions. This will cause 
an overestimation of $\mathrm{N}$ uptake. The model should be extended with a description of biologically controlled nutrient uptake to simulate uptake under these conditions. No effort has been made to describe nutrient uptake by first order or Michaelis-Menten kinetics, because too little is known about the required parameters and their dependence on root age, state of development of the plant and nutrient status of the plant.

The satisfactory prediction of $\mathrm{N}$ uptake in cases where $\mathrm{N}$ is growth limiting throughout the experiment indicates that the presented equations that describe the effects of inter-root competition and increasing root density on nutrient uptake are powerful.

\section{Acknowledgements}

The authors are very grateful to Dr ir J Goudriaan for his valuable suggestions in the development of the simulation model. Thanks are also due to Mr E Heij for analytical assistance and to Dr ir B H Janssen for his useful comments on the manuscript.

\section{References}

Baldwin J P, Nye P H and Tinker P B 1973 Uptake of solutes by multiple root systems from soil. III. A model for calculating the solute uptake by a randomly dispersed root system developing in a finite volume of soil. Plant and Soil $38,621-635$.

Brewster J L, Bhat K K S and Nye P H 1975 The possibility of predicting solute uptake and plant growth response from independently measured soil and plant characteristics. III. The growth and uptake of onions in a soil fertilized to different initial levels of phosphate and a comparison of the results with model predictions. Plant and Soil 42, 197-226.

Claassen N and Barber S A 1976 Simulation model for nutrient uptake from soil by a growing plant root system. Agron. J. 68, 961-964.

Crank J 1975 The Mathematics of Diffusion, 2nd edition. Clarendon Press, Oxford, 414 p.

Cushman J H 1979 An analytical solution to solute transport near root surfaces for low initial concentration. I. Equations development. Soil Sci. Soc. Am. J. 43, 1087-1090.

Hoffland E, Findenegg G R and Nelemans J A 1989 Solubilization of rock phosphate by rape. I. Evaluation of the role of the nutrient uptake pattern. Plant and Soil 113, 155160.

Nye P H 1966 The effect of the nutrient intensity and buffering power of a soil, and the absorbing power, size and root hairs of a root, on nutrient absorption by diffusion. Plant and Soil 25, 81-105.

Nye P H 1968 The use of exchange isotherms to determine diffusion coefficients in soil. 9th Int. Cong. Soil Sci. Trans. (Adelaide) 1, 117-126.

Nye P H and Tinker P B 1977 Solute Movement in the Soil-Root System. Blackwell Scientific Publications, Oxford, $342 \mathrm{p}$.

Nye P H, Brewster J L and Bhat K K S 1975 The possibility of predicting solute uptake and plant growth response from independently measured soil and plant characteristics. I. The theoretical basis of the experiments. Plant and Soil 42, 161-170.

Russell R S 1977 Plant Root Systems: Their Function and Interaction with the Soil. McGraw-Hill Book Company, London, 298 p.

Silberbush M and Barber S A 1983 Prediction of potassium uptake by soybeans with a mechanistic mathematical model. Soil Sci. Soc. Am. J. 47, 262-265.

Vaidyanathan L V and Nye P H 1966 The measurement and mechanism of ion diffusion in soils. II. An exchange resin paper method for measurement of the diffusive flux and diffusion coefficient of nutrient ions in soils. J. Soil Sci. 17, 175-183.

Van der Zee S E A T M, Fokkink L G J and Van Riemsdijk W H 1987 A new technique for assessment of reversibly adsorbed phosphate. Soil Sci. Soc. Am. J. 51, 599-604. 
